\title{
NÍVEIS DE IRRIGAÇÃO E DE COMPOSTO DE LIXO ORGÂNICO NA FORMAÇÃO DE MUDAS CÍTRICAS EM CASA DE VEGETAÇÃ ${ }^{1}$
}

\author{
EMERSON FACHINI ${ }^{2}$, JOÃO A. GALBIATTI ${ }^{3}$, LUIZ C. PAVANI ${ }^{4}$
}

\begin{abstract}
RESUMO: O presente trabalho visou a estudar o efeito da associação entre a irrigação e tipos de substratos na formação de mudas de laranjeira. $\mathrm{O}$ delineamento experimental utilizado foi o de blocos casualizados, com parcelas subdivididas, com quatro repetições, três níveis de irrigação e cinco tipos de substratos. Foram utilizados os seguintes substratos: $100 \%$ de casca de pínus; $80 \%$ de casca de pinus $+20 \%$ de composto de lixo orgânico; $60 \%$ de casca de pinus $+40 \%$ de composto de lixo orgânico; $20 \%$ de casca de pinus $+80 \%$ de composto de lixo orgânico, e $100 \%$ de composto de lixo orgânico. A irrigação por gotejamento foi feita com lâminas de 50\%, 100\% e 150\% da evaporação do atmômetro modificado. A avaliação do desenvolvimento das plantas foi feita quinzenalmente, medindo-se o diâmetro do caule e a altura. Os resultados mostraram que as mudas de citrus apresentaram necessidade de água variável com os diferentes estádios de desenvolvimento e tipos de substratos, dos quais se destacou o substrato 3 (60\% de casca de pinus e 40\% de composto de lixo urbano), pois propiciou melhores condições para o desenvolvimento das raízes das plantas e também forneceu nutrientes, por meio da decomposição do material orgânico. A irrigação 3 (150\% da evaporação do atmômetro) foi a que proporcionou o melhor desenvolvimento das mudas de laranjeira.
\end{abstract}

PALAVRAS-CHAVE: irrigação, substratos, mudas cítricas.

\section{LEVELS OF IRRIGATION AND TYPES OF SUBSTRATE UTILIZING ORGANIC WASTE COMPOST, IN THE PRODUCTION OF ORANGE TREES}

SUMMARY: The research studied the association between irrigation levels and types of substrate utilizing organic waste compost, in the production of orange trees. A randomized block experiment design with split plots, with four repetition, three levels of irrigation and five types of substrate was used. The substrates were: $100 \%$ pine bark, $80 \%$ pine bark $+20 \%$ organic waste compound, $60 \%$ pine bark $+40 \%$ organic waste compound, $20 \%$ pine bark $+80 \%$ organic waste compound, and $100 \%$ organic waste compound. The irrigation levels were 50\%, 100\% and $150 \%$ the evaporation of modified atmometer, and the irrigation was done by dropping system. The development valuation was done fortnightly, been measured diameter and height of the plant. The results showed that, orange trees need different levels of water in different stage of development and types of substrate, the substrate 3 (60\% pine bark $+40 \%$ organic waste compound) detached from the others because it gave better condition to development of the plant roots and disposal of nutrients by decomposition of organic waste compost. The irrigation 3 (150\% the evaporation of modified atmometer) propitiated better development to orange trees.

KEYWORDS: irrigation, substrate, orange tree.

\footnotetext{
${ }^{1}$ Trabalho financiado pela FAPESP

${ }^{2}$ Doutorando em Irrigação e Drenagem, UNESP - Câmpus de Botucatu. Rua Floriano Peixoto, 157, Monte Azul Paulista - SP.

${ }^{3}$ Professor Titular, Departamento de Engenharia Rural, UNESP - Câmpus de Jaboticabal.

${ }^{4}$ Professor Titular, Departamento de Engenharia Rural, UNESP - Câmpus de Jaboticabal.

Recebido pelo Conselho Editorial em: 30-4-2002

Aprovado pelo Conselho Editorial em: 2-7-2004
} 


\section{INTRODUÇÃO}

Após a revolução industrial, houve aumento do êxodo rural, fazendo com que as cidades hoje estejam superpovoadas, resultando em qualidade de vida cada vez pior devido, entre outros fatores, ao acúmulo de lixo e à degradação da qualidade da água.

Uma cidade com 400 mil habitantes produz, em média, $300.000 \mathrm{~kg}$ de lixo por dia, composto basicamente dos seguintes elementos: $22 \%$ de metais, papéis, vidros e plásticos; $56 \%$ de orgânicos, compreendendo restos de alimentos, verduras, legumes, frutas e resíduos de podas de jardim e gramas; $2 \%$ de lixo séptico de hospitais, ambulatórios, farmácias, postos de saúde e laboratórios, e $20 \%$ de rejeitos inertes de difícil reciclagem (CONSTRUFERT, s.d.). Alguns materiais demoram muito tempo para serem decompostos, como exemplo temos o papel que demora mais ou menos seis meses, latas e metais demoram mais de 100 anos e vidro demora 1 milhão de anos.

Com relação à disponibilidade de água, estudiosos acreditam que, em 2025, dois terços da população mundial sofrerão com a escassez desse importante recurso natural (OLIVER, 2000).

Com o advento da irrigação, foi possível aumentar a produção de várias culturas e produzir em locais que eram impossíveis, por falta de chuvas. Muitas vezes a irrigação é feita sem critérios, causando desperdício de grande quantidade de água que poderia ser aproveitada mais eficientemente.

Sistemas modernos de irrigação estão diminuindo cada vez mais a quantidade de água aplicada, colocando-a no local certo. Na divisão do consumo de água mundial, a agricultura é responsável atualmente por $65 \%$ do consumo total de água, em que o motivo é a expansão da agricultura irrigada; a indústria é responsável por 25\%, e o uso doméstico por 10\% (OLIVER, 2000).

Caso seja possível utilizar o lixo orgânico e águas de esgoto na agricultura, os problemas ambientais serão reduzidos.

Uma das utilidades que se pode dar ao lixo orgânico tratado é a formação de substrato para uso na produção de mudas de plantas comerciais, como a laranjeira. Segundo STURION (1981), o substrato tem como principal função sustentar a planta e fornecer-lhe nutrientes. É composto de uma parte sólida (partículas minerais e orgânicas) e de espaços porosos que podem ser ocupados pela água e/ou ar. O desenvolvimento e a eficiência do sistema radicular são grandemente influenciados pelo grau de aeração do solo, dependente da quantidade, do arranjamento e do tamanho das partículas que definem sua textura.

No ano de 2001-2002, o Brasil produziu 13.760.496 t de laranja, correspondendo a 33\% da produção mundial, sendo o maior produtor. O segundo maior produtor foram os EUA, com $15 \%$ da produção mundial, equivalendo a menos da metade da produção brasileira. Atualmente, há grande demanda e competição no mercado de produtos gerados pela citricultura. O Brasil é o maior produtor mundial de cítrus e de suco de laranja, responsável por mais de 400 mil empregos diretos e US\$ 1,5 bilhão em divisas anuais, sendo fundamental na economia de 204 municípios do Estado de São Paulo (AGRIANUAL, 2003).

Os problemas que a exploração da cultura do cítrus enfrenta em nosso País são sérios, sobretudo sob o ponto de vista de produzir plantas altamente produtivas e com alta longevidade. Para isso, o alicerce da citricultura moderna é a produção de mudas com técnicas que resultem em plantas vigorosas e, conseqüentemente, com maior potencial produtivo.

O objetivo do presente trabalho foi estudar os efeitos de diferentes níveis de irrigação e utilização de lixo orgânico como substrato na produção de mudas de laranjeira. 


\section{MATERIAL E MÉTODOS}

A pesquisa foi realizada em casa de vegetação do Setor de Fruticultura, UNESP - Câmpus de Jaboticabal, localizada a $21^{\circ} 15^{\prime} 22^{\prime \prime}$ de latitude sul, $48^{\circ} 18^{\prime} 58^{\prime \prime}$ de longitude oeste (IBGE, 1971) e a $575 \mathrm{~m}$ de altitude.

O clima, segundo a classificação de Köeppen, é do tipo subtropical com inverno seco (Cwa), com precipitação média anual de $1.400 \mathrm{~mm}$, temperatura média anual de $22{ }^{\circ} \mathrm{C}$ e umidade relativa média do ar de $70 \%$. A casa de vegetação é coberta com filme de plástico transparente de $200 \mu \mathrm{m}$, cercada lateralmente com tela (malha de $2 \mathrm{~mm}^{2}$ de cor branca) e pé-direito de 4,5 $\mathrm{m}$ de altura. As bancadas são de alvenaria com $60 \mathrm{~cm}$ de altura, $80 \mathrm{~cm}$ de largura e $2 \mathrm{~m}$ de comprimento. $\mathrm{O}$ comprimento das bancadas e das linhas de plantio foi na direção norte-sul, perpendicularmente ao comprimento da estufa construída no direção leste-oeste. Essa técnica está de acordo com SGANZERLA (1991), pois as linhas de plantio dentro da estufa devem estar dispostas de tal forma que plantas não façam sombra às outras, e isso é conseguido com o alinhamento dos canteiros no sentido norte-sul, pois as plantas recebem aproximadamente a mesma quantidade de energia.

\section{Delineamento experimental}

O delineamento experimental foi o de blocos casualizados, com parcelas subdivididas, com quatro repetições, em que as parcelas corresponderam a três níveis de irrigação e as subparcelas a cinco tipos de substratos, com seis mudas de laranja cada.

Os substratos utilizados foram os seguintes:

S1 - 100\% de casca de pínus;

S2 - mistura de $80 \%$ de casca de pínus e $20 \%$ de lixo orgânico;

S3 - mistura de $60 \%$ de casca de pínus e $40 \%$ de lixo orgânico;

S4 - mistura de $20 \%$ de casca de pínus e $80 \%$ de lixo orgânico, e

S5 - 100\% de composto de lixo orgânico.

As lâminas de irrigação foram calculadas baseando-se em:

I1 - 50\% da evaporação medida no atmômetro modificado;

I2 - 100\% da evaporação medida no atmômetro modificado, e

I3 - 150\% da evaporação medida no atmômetro modificado.

\section{Condução do experimento}

O composto de lixo orgânico foi adquirido em uma usina de separação de lixo, na cidade de Araraquara - SP. O composto foi deixado durante 80 dias amontoado ao ar livre para que o processo de compostagem se completasse.

Antes do enchimento dos recipientes, foi realizada a esterilização dos substratos com brometo de metila. A esterilização teve intuito de deixar o material livre de patógenos (principalmente nematóides e fungo Phythophytora). As mudas foram plantadas em recipientes cilíndricos de plástico com tamanho de $20 \mathrm{~cm}$ x $40 \mathrm{~cm}$ e capacidade para 4,5 L. A casca de pínus e o composto de lixo foram misturados nas proporções descritas anteriormente, juntamente com a adubação de plantio.

Após o acondicionamento dos recipientes de plástico nas bancadas, foi realizada uma irrigação manual para umedecimento dos substratos. Quando os recipientes com substrato pararam de drenar, foi realizado o plantio das mudas dos porta-enxertos de citrumelo swingle ou 4475 (Poncirus trifoliata $x$ Citrus paradisi), adquiridas de viveirista. Após o plantio, os porta-enxertos foram submetidos 
igualmente à irrigação manual, durante uma semana, para que os mesmos tivessem boa fixação no substrato. A repicagem dos porta-enxertos para os recipientes plásticos foi realizada no dia 6-8-2000, onde foi colocado apenas um porta-enxerto por recipiente. A partir do pegamento dos porta-enxertos, foi feito o acompanhamento da altura da planta, medindo-se com uma régua, graduada $\mathrm{em} \mathrm{cm}$, da superfície do solo à folha mais alta.

A enxertia foi feita quando o caule do porta-enxerto atingiu um diâmetro médio de 9 a $10 \mathrm{~mm}$ a um centímetro do colo da planta, equivalendo a $7 \mathrm{~mm}$ de diâmetro, a $15 \mathrm{~cm}$ do colo, onde a enxertia foi feita com borbulhas de laranjeira "Valência". As plantas atingiram o ponto de serem levadas para o campo quando os enxertos apresentaram altura maior que $50 \mathrm{~cm}$ e ramo maduro, que era identificado pela maior resistência ao dobramento (GRASSI FILHO et al., 2001 e LIMA, 1993).

Quando as plantas atingiram o ponto de serem levadas para o campo, as mesmas foram desfolhadas com o objetivo de realizar a análise química foliar, bem como uma avaliação do estado nutricional.

\section{Caracterização qualitativa do substrato}

Para a caracterização dos substratos, foram realizadas análises química e física, segundo metodologia descrita por KIEHL (1985), cujos resultados estão apresentados nas Tabelas 1 e 2. As análises química e física foram realizadas no laboratório de solos da ESALQ-USP, em Piracicaba - SP.

TABELA 1. Dados da análise física dos substratos.

\begin{tabular}{|c|c|c|}
\hline Atributos & Composto de Lixo & Casca de Pínus \\
\hline & & \\
\hline Densidade aparente & 0,77 & 0,50 \\
\hline Densidade real & 0,91 & 0,91 \\
\hline Condutividade elétrica & 2,19 & 2,85 \\
\hline
\end{tabular}

TABELA 2. Dados da análise química dos substratos.

\begin{tabular}{|c|c|c|}
\hline Atributos & Composto de Lixo & Casca de Pínus \\
\hline$\overline{\mathrm{pH} \text { em } \mathrm{CaCl}_{2} 0,01 \mathrm{M}}$ & 7,8 & 5,3 \\
\hline Relação C/N (C orgânico e N total) & $15 / 1$ & $58 / 1$ \\
\hline Umidade total & 17 & 41 \\
\hline Matéria orgânica total (combustão) & 25,75 & 31,5 \\
\hline Matéria orgânica compostável & 25 & 30 \\
\hline Nitrogênio total & 1,05 & 0,29 \\
\hline Fósforo total & 0,74 & 0,42 \\
\hline Potássio total & 0,26 & 0,16 \\
\hline Cálcio total & 1,73 & 0,97 \\
\hline Magnésio total & 0,20 & 1,05 \\
\hline Enxofre total & 0,19 & 0,21 \\
\hline Cobre total & \multicolumn{2}{|c|}{$\mathrm{mg} \mathrm{kg}^{-1}$} \\
\hline Manganês total & 245 & 325 \\
\hline Zinco total & 475 & 57 \\
\hline Ferro total & 29.460 & 18.731 \\
\hline Sódio total & 1.785 & 464 \\
\hline
\end{tabular}




\section{Irrigação}

\section{Equipamento desenvolvido}

A irrigação das mudas foi feita individualmente em cada recipiente pelo sistema por gotejamento. Para que a distribuição da água nas parcelas correspondentes às lâminas de irrigação fosse feita uniformemente, foi desenvolvido um equipamento de irrigação por gotejamento composto por um tubo de PVC de 6", com $50 \mathrm{~cm}$ de altura, fechado na extremidade inferior por um CAP de PVC, onde foram acoplados os 30 emissores que irrigavam as 30 plantas por parcela. Na extremidade superior do tubo por onde era inserida a água, foram instalados dois filtros de tecido de algodão, sendo um de cor branca (superior), e o que se localizava por debaixo do primeiro, era de cor preta para permitir a passagem da água e impedir a passagem de luz, evitando o desenvolvimento de fungos dentro do tubo, o que poderia ocasionar o entupimento dos emissores. Como emissores, foram utilizados Equipo de Infusão de uso médico, provido de microgotas.

\section{Controle da irrigação}

Utilizou-se o atmômetro modificado, recomendado por BRONER \& LAW (1991), para estimar a evapotranspiração de referência, cujas medidas de evaporação foram tomadas como base para definir as lâminas de água a serem aplicadas na irrigação.

A irrigação foi realizada quando a evaporação acumulada lida no atmômetro modificado atingiu o valor mínimo de $5 \mathrm{~mm}$, devido à precisão do aparelho de irrigação, que apresentava melhor distribuição de água a partir desse patamar. Quando a irrigação era realizada com lâminas menores que $5 \mathrm{~mm}$, a coluna de água no reservatório do aparelho de irrigação era pequena, o que provocava desuniformidade na saída da água. A irrigação foi feita em duas etapas, com intervalos de seis horas, para evitar percolação de água.

\section{Adubação}

A adubação de plantio foi a mesma para todos os tratamentos, baseando-se em recomendação utilizada pelos produtores de mudas de laranjeira na região de Monte Azul Paulista - SP. Cada recipiente recebeu uma adubação, para cada $\mathrm{m}^{3}$ de substrato, equivalente a $3 \mathrm{~kg}$ do adubo peletizado da fórmula 14-14-14 e $2 \mathrm{~kg}$ de superfosfato simples. A mistura dos fertilizantes foi realizada individualmente para cada recipiente. Mensalmente, realizou-se adubação foliar utilizando 2,5 $\mathrm{g}$ do produto comercial diluídos em 2 litros de água. As características do adubo foliar estão na Tabela 3.

TABELA 3. Composição do adubo foliar utilizado.

\begin{tabular}{lc}
\hline Nutrientes & Proporção em Peso (\%) \\
\hline Nitrogênio & 10,0 \\
Zinco & 6,0 \\
Enxofre & 3,5 \\
Boro & 3,0 \\
Cálcio & 1,5 \\
Magnésio & 1,0 \\
Ferro & 0,5 \\
Manganês & 0,5 \\
Cobre & 0,5 \\
Molibdênio & 0,05 \\
\hline
\end{tabular}

Juntamente com a adubação foliar, foram colocados $2 \mathrm{~g}$ de produto comercial contendo oxicloreto de cobre $\left(840 \mathrm{~g} \mathrm{~kg}^{-1}\right)$ que, além de atuar como fungicida, também atua como fornecedor de $\mathrm{Cu}$. 


\section{RESULTADOS E DISCUSSÃO}

\section{Plantas aptas para o plantio}

Quando as mudas atingiram o porte de serem transplantadas ao campo, essas apresentavam diferenças com relação aos tratamentos adotados.

$\mathrm{Na}$ Tabela 4, evidencia-se que o valor de $\mathrm{F}$ foi significativo, a $1 \%$ de probabilidade, para níveis de irrigação e para tipos de substratos, indicativo de que existem diferenças dentro desses fatores.

$\mathrm{O}$ valor de $\mathrm{F}$ também foi significativo, a $1 \%$ de probabilidade, para a interação entre irrigação e substrato, evidenciando que os fatores níveis de irrigação e tipos de substrato atuaram conjuntamente sobre o desenvolvimento das plantas.

TABELA 4. Análise de variância dos dados de época do plantio das mudas no campo.

\begin{tabular}{lcrrr}
\hline Causas Variação & GL & \multicolumn{1}{c}{ SQ } & \multicolumn{1}{c}{ QM } & \multicolumn{1}{c}{ F } \\
\hline Blocos & 3 & 510,6000 & 170,2000 & $2,90^{\mathrm{NS}}$ \\
Irrigação (I) & 1 & $18.147,6000$ & $18.147,6000$ & $309,69 * *$ \\
Resíduo (A) & 3 & 175,8000 & 58,6000 & \\
\hline (parcelas) & $(7)$ & $18.834,0000$ & & $34,16^{* *}$ \\
Substrato (S) & 4 & $15.554,2500$ & $3.888,5625$ & $24,09 * *$ \\
Interação I x S & 4 & $10.696,6500$ & $2.742,4125$ & \\
Resíduo (B) & 24 & $2.732,1000$ & 113,8375 & \\
\hline Total & 39 & $48.090,0000$ & & \\
\hline
\end{tabular}

C.V. para parcelas $=2,36 \%$; C.V. para subparcela $=3,28 \%$

Os resultados do teste de Tukey para os diferentes níveis de irrigação e tipo de substrato estão apresentados na Tabela 5. As plantas da irrigação 3 (I3) atingiram o porte para serem transplantadas para o campo, anteriormente às plantas da irrigação 2 (I2).

TABELA 5. Resultado dos tratamentos de níveis de irrigação e composição dos substratos no tempo médio, em dias, para que as mudas atingissem porte de serem transplantadas.

\begin{tabular}{cccccccc}
\hline \multicolumn{7}{c}{ Tratamentos } \\
\hline \multicolumn{7}{c}{ Níveis de Irrigação (DMS=8)* } & \multicolumn{5}{c}{ Substratos (DMS=15)** } \\
\hline I1 & I2 & I3 & S1 & S5 & S4 & S2 & S3 \\
$\# \#$ & 346A & 304B & 349a & $347 \mathrm{a}$ & $317 \mathrm{~b}$ & $314 \mathrm{~b}$ & $298 \mathrm{c}$ \\
\hline
\end{tabular}

* Letras maiúsculas iguais indicam que as médias não diferem entre si, a 5\% de probabilidade, pelo teste de Tukey.

** Letras minúsculas iguais indicam que as médias não diferem entre si, a 5\% de probabilidade, pelo teste de Tukey.

\#\# I1 não atingiu o ponto de enxertia.

O substrato que promoveu o mais rápido desenvolvimento das plantas foi o do tratamento S3, fazendo com que as plantas em um tempo menor estivessem prontas para o plantio. Os substratos que promoveram o menor desenvolvimento das plantas foram os dos tratamentos S1 e S5. Nos substratos 2 e 4, as plantas tiveram desenvolvimento intermediário.

O substrato do tratamento $\mathrm{S} 3$ condicionou maior desenvolvimento das raízes e, em consequiência disso, maior desenvolvimento das plantas. Até o ponto de enxertia, esse substrato apresentou, estatisticamente, desenvolvimento das plantas igual aos substratos 1;2 e 4. O seu melhor desempenho, no final do ciclo, está relacionado com a disponibilidade de água mais adequada em relação aos demais substratos, propiciando às plantas melhor desenvolvimento, segundo MILNER (2001). 
Outro fator importante foi o fornecimento de nutrientes pela decomposição da matéria orgânica. A mistura de casca de pínus e lixo orgânico na proporção feita no substrato 3 (S3) mostrou-se bastante efetiva com relação ao fornecimento de nutrientes. As plantas do substrato 3 não apresentaram deficiência visual após a estabilização da decomposição do material orgânico (primeiros 60 dias após o transplantio), enquanto as plantas do substrato 1, apesar das adubações foliares realizadas quinzenalmente, apresentaram sintomas visuais marcantes de deficiência de nutrientes depois que o fertilizante de liberação lenta deixou de atuar, evidenciando que esse substrato não teve capacidade própria de manter as plantas supridas de nutrientes todo o tempo necessário. Esse fato concorda com STRINGHETA et al. (1996), que obtiveram aumento de altura das plantas de crisântemo à medida que a concentração de composto de lixo aumentou até $45,76 \%$, e, em concentrações maiores, ocorreu redução na altura das plantas.

O nível 3 de irrigação condicionou bom desempenho até o final do experimento e as plantas desse tratamento obtiveram o melhor desenvolvimento durante todo o ciclo. Como já foi relatado, esse nível de irrigação foi o que proporcionou o melhor "status" hídrico às plantas. No substrato 5, que apresentava alta concentração de alguns nutrientes, principalmente de $\mathrm{N}$, o nível 3 de irrigação promoveu lixiviação de substâncias e nutrientes, diminuindo a concentração desses no substrato e, consequientemente, nas plantas, atenuando assim a toxicidade e melhorando o seu desenvolvimento. Esse fato pode ser comprovado observando a análise foliar (Tabela 6).

Os valores referentes à interação entre os tratamentos irrigação e substrato, estão apresentados na Tabela 6. Os substratos não afetaram o tempo gasto pelas plantas para completarem o seu desenvolvimento para serem plantadas no campo na irrigação 2 (I2), pois não houve diferença estatística entre as médias.

TABELA 6. Tempo médio, em dias, até as mudas atingirem o porte de serem transplantadas para o campo para médias do desdobramento de substratos dentro de irrigação e de irrigação dentro de substratos.*

\begin{tabular}{ccc}
\hline \multirow{2}{*}{ Substratos } & \multicolumn{3}{c}{ Níveis de Irrigação } \\
\cline { 2 - 3 } & I2 & I3 \\
\hline S1 & $349 \mathrm{~A} \mathrm{a}$ & $349 \mathrm{~A} \mathrm{a}$ \\
S2 & $349 \mathrm{~A} \mathrm{a}$ & $279 \mathrm{BC} \mathrm{b}$ \\
S3 & $336 \mathrm{~A} \mathrm{a}$ & $261 \mathrm{C} \mathrm{b}$ \\
S4 & $349 \mathrm{~A} \mathrm{a}$ & $285 \mathrm{~B} \mathrm{~b}$ \\
S5 & $349 \mathrm{~A} \mathrm{a}$ & $345 \mathrm{~A} \mathrm{a}$ \\
\hline
\end{tabular}

DMS - colunas: 22

DMS - linhas: 15

* Médias seguidas por letras iguais, maiúscula nas colunas e minúscula nas linhas, não diferem entre si, a 5\% de probabilidade, pelo teste de Tukey.

As interações que mais se destacaram foram o nível de irrigação 3 com o substrato 3 (I3S3) e o nível de irrigação 3 com o substrato 2 (I3S2), promovendo o melhor desenvolvimento das mudas. Apesar de não haver diferença estatística entre os substratos 2 e 3, o substrato 3 proporcionou melhor desenvolvimento dos enxertos, e as plantas atingiram o tamanho adequado para serem transplantadas 18 dias antes do que as plantas do substrato 2. Os substratos 2 (S2) e 4 (S4), nesse nível de irrigação, proporcionaram desempenho intermediário no desenvolvimento das plantas, e as mesmas se desenvolveram mais lentamente nos substratos 1 e 5 .

O nível de irrigação 3 (I3) proporcionou o melhor desenvolvimento das plantas até atingirem o desenvolvimento adequado para serem levadas ao campo, como está apresentado nas Tabelas 4; 5 e 6. 
Esse fato, provavelmente, foi devido à necessidade de água pelas plantas, suprida mais adequadamente pelo nível de irrigação 3 .

Segundo FOLEGATTI et al. (1997), a casa de vegetação promove uma alteração no microclima do local, e a temperatura interna é maior que a externa. Com a maior temperatura, a planta tem uma taxa de transpiração maior, aumentando a necessidade de água pela planta. Plantas crescendo em estufas com irrigação freqüente apresentaram um fluxo transpiratório intenso, fazendo com que as plantas necessitem de alta quantidade de água para a sua manutenção. Esse fato ajuda a explicar por que a irrigação 3 (I3) promoveu o melhor desenvolvimento das plantas.

As mudas cultivadas em vasos dispõem de um ambiente restrito para a absorção de água e nutrientes pelas raízes; sendo assim, os mesmos têm de ser fornecidos adequadamente para que as plantas possam apresentar bom desenvolvimento.

\section{Avaliação nutricional das folhas das mudas cítricas}

$\mathrm{Na}$ avaliação dos dados de nutrientes na análise foliar (Tabela 7), em comparação com os dados utilizados para a interpretação dos teores de macro e micronutrientes nas folhas de citros, publicados por VIOLANTE NETTO et al. (1988), é possível evidenciar o provável fator do amarelecimento das plantas do substrato 1 nos três níveis de irrigação.

TABELA 7. Conteúdo de nutrientes nas folhas de mudas de laranja 'Valência' sobre o porta-enxerto Citrumelo Swingle.**

\begin{tabular}{|c|c|c|c|c|c|c|c|c|c|c|c|}
\hline Tratamentos & $\mathrm{N}$ & $\mathrm{P}$ & $\mathrm{K}$ & $\mathrm{Ca}$ & $\mathrm{Mg}$ & $S$ & B & $\mathrm{Cu}$ & $\mathrm{Fe}$ & Mn & $\mathrm{Zn}$ \\
\hline & & & $\mathrm{kg}^{-1}$ & & & & & & & & \\
\hline *I1S1 & 18,9 & 1,3 & 15,2 & 23,9 & 4,3 & 5,6 & 209 & 505 & 106 & 69 & 51 \\
\hline *I1S2 & 25,6 & 1,1 & 11,7 & 23,9 & 3,0 & 2,7 & 150 & 400 & 111 & 74 & 54 \\
\hline *I1S3 & 27,0 & 1,1 & 13,1 & 24,1 & 2,8 & 2,3 & 146 & 745 & 133 & 62 & 62 \\
\hline *I1S4 & 42,0 & 0,7 & 35,9 & 23,2 & 1,8 & 2,5 & 95 & 405 & 88 & 21 & 33 \\
\hline *I1S5 & 41,7 & 0,7 & 54,0 & 19,6 & 1,3 & 2,4 & 97 & 143 & 74 & 15 & 31 \\
\hline $\mathrm{I} 2 \mathrm{~S} 1$ & 22,8 & 1,8 & 32,7 & 19,0 & 3,2 & 3,6 & 160 & 67 & 756 & 28 & 42 \\
\hline $\mathrm{I} 2 \mathrm{~S} 2$ & 25,2 & 1,4 & 24,0 & 25,8 & 2,8 & 3,1 & 94 & 330 & 168 & 32 & 93 \\
\hline $\mathrm{I} 2 \mathrm{~S} 3$ & 25,9 & 1,4 & 23,6 & 20,7 & 2,8 & 2,5 & 80 & 197 & 96 & 23 & 95 \\
\hline $\mathrm{I} 2 \mathrm{~S} 4$ & 40,3 & 0,7 & 38,0 & 21,0 & 2,0 & 2,2 & 83 & 285 & 139 & 10 & 82 \\
\hline I2S5 & 39,6 & 0,8 & 37,4 & 19,6 & 1,6 & 2,1 & 74 & 8 & 38 & 5 & 25 \\
\hline I3S 1 & 16,1 & 3,0 & 40,0 & 21,0 & 3,4 & 4,5 & 261 & 475 & 150 & 20 & 115 \\
\hline I3S2 & 18,9 & 1,4 & 31,4 & 19,8 & 3,1 & 2,2 & 155 & 445 & 198 & 23 & 115 \\
\hline I3S3 & 24,5 & 1,4 & 30,2 & 19,4 & 2,7 & 2,5 & 140 & 715 & 222 & 22 & 131 \\
\hline $\mathrm{I} 3 \mathrm{~S} 4$ & 32,2 & 0,8 & 36,1 & 19,8 & 2,5 & 2,2 & 125 & 670 & 206 & 14 & 141 \\
\hline I3S5 & 32,9 & 0,7 & 33,0 & 22,6 & 2,1 & 2,2 & 86 & 197 & 98 & 8 & 95 \\
\hline
\end{tabular}

* No tratamento I1, a análise foi feita com as folhas do porta-enxerto, pois as plantas não atingiram o ponto de enxertia. ** Análise feita na UNESP - Câmpus Jaboticabal, no Departamento de Solos e Adubos.

Os dados da análise evidenciam que o teor de nitrogênio foi baixo ou deficiente nas plantas desse substrato. A decomposição de material orgânico com relação C/N entre 60:1 e 80:1, normalmente, faz com que o nível de nitrogênio disponível diminua por algum tempo, devido ao fato de estar sendo utilizado por microorganismos para fazer a decomposição do material. O substrato 1 (S1), no início do experimento, apresentava relação $\mathrm{C} / \mathrm{N}$ de 65:1 e, no final, a relação diminui para 41:1. A planta utilizou o $\mathrm{N}$ aplicado via fertilizante para suprir suas necessidades no início do desenvolvimento. Enquanto o fertilizante estava disponibilizando o nutriente para as plantas, essas obtiveram bom 
desenvolvimento, porém com a diminuição gradual da ação do fertilizante, as plantas começaram a apresentar sintomas de deficiência de $\mathrm{N}$.

Com relação às plantas dos substratos 4 e 5 , em todos níveis de irrigação, os dados mostram que as mesmas estavam com os teores excessivos de nitrogênio nas folhas. Esse excesso está relacionado com a decomposição do material orgânico, fato que concorda com dados obtidos por VINTEN \& SMITH (1993), que relatam o processo de mineralização do material orgânico, o qual transforma o nitrogênio da forma orgânica, que não pode ser aproveitado pelas plantas, para a forma mineral que pode sê-lo. Sendo o nitrogênio absorvido por fluxo de massa e sua concentração alta na solução do substrato devido à mineralização, a planta absorve esse elemento em grande quantidade, podendo causar sintomas de toxidez nas folhas.

As plantas dos substratos 2 e 3 apresentam teores de nitrogênio adequados às folhas, resultados semelhantes aos obtidos por VIOLANTE NETO et al. (1988). Houve decréscimo no teor de nitrogênio com o aumento do nível de irrigação, podendo ter ocorrido a diluição desse nutriente pelo maior desenvolvimento da planta (Figura 1). O nitrogênio é o nutriente que apresenta alta mobilidade gerenciada pelo fluxo de massa, estando intimamente relacionado com o movimento e a quantidade de água na planta. Já a perda de nitrogênio por lixiviação, nos solos agricultáveis, está relacionada com a quantidade de precipitação anual (ARMSTRONG \& BURT, 1993).

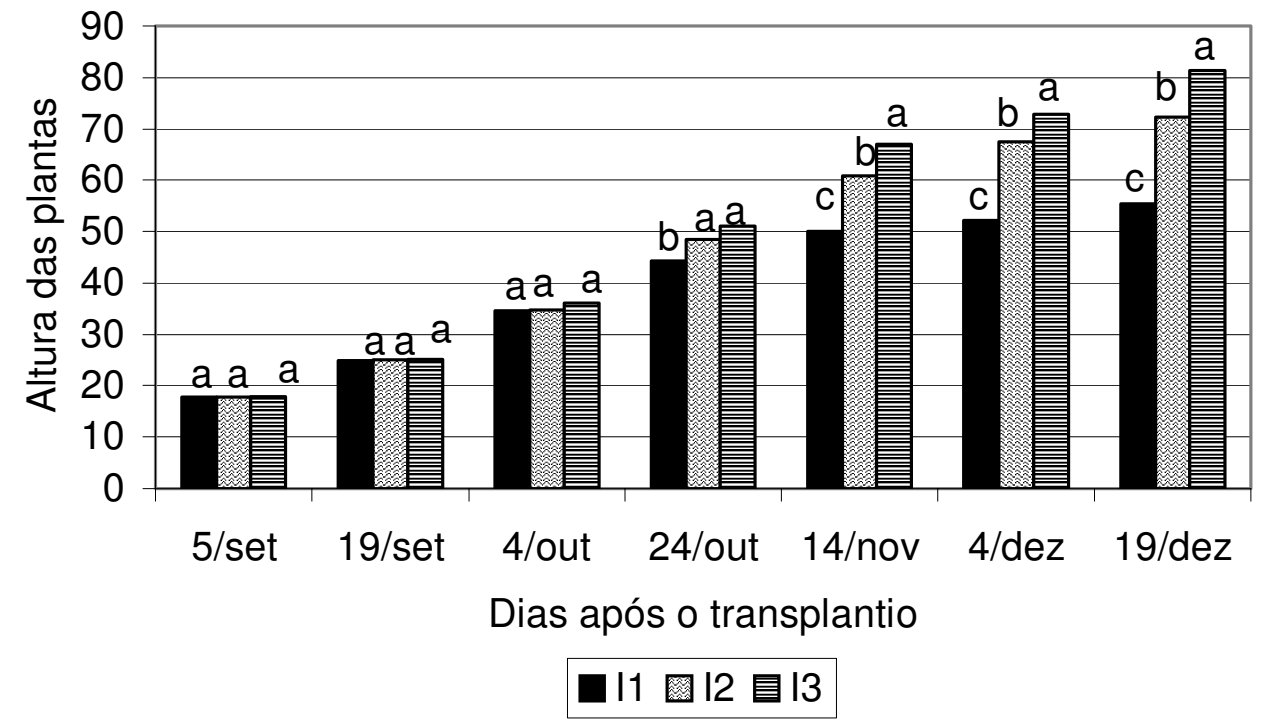

Letras minúsculas iguais indicam que as médias não diferem entre si, a 5\% de probabilidade, pelo teste de Tukey

I1 - 50\% da evaporação medida no atmômetro modificado

I2 - $100 \%$ da evaporação medida no atmômetro modificado

I3 - 150\% da evaporação medida no atmômetro modificado

FIGURA 1. Altura das plantas, em cm, dentro de níveis de irrigação.

No substrato 1, as plantas apresentaram (em todas as irrigações) altos teores de boro nas folhas. Segundo MATTOS et al. (1995), a planta cítrica é muito sensível à toxidez de boro, e o sintoma é uma clorose que se desenvolve da borda para o centro do limbo foliar, caracterizado por um mosqueamento $\mathrm{e}$, em alguns casos, pontuações, pela necrose do tecido, sempre nas folhas mais velhas.

As plantas apresentaram teores decrescentes de fósforo $(\mathrm{P})$ com o aumento da quantidade de composto de lixo no substrato. Esse fato diferencia-se dos dados apresentados por ALCOFORADO \& TRINDADE (1993) e por HERNANDEZ et al. (1992), que constataram aumentos lineares de fósforo, 
potássio, cálcio e magnésio ao aplicarem doses crescentes de composto orgânico de lixo. Essa afirmação pode ser explicada por BERNARDI et al. (2000), que relatam que os teores de P nas plantas são inversamente proporcionais aos teores de $\mathrm{N}$, ou seja, tratamento com $\mathrm{N}$ excessivo nas plantas provoca diminuição na concentração $\mathrm{P}$ motivado pela concorrência entre eles, e a análise das plantas do experimento mostra que, nas plantas dos substratos 4 e 5, apresentavam teores altos e excessivos de $\mathrm{N}$ e baixos de $\mathrm{P}$.

As plantas dos tratamentos S2 e S3 foram as que apresentaram o melhor equilíbrio de nutrientes; porém, na irrigação 3 (I3), as plantas do substrato 2 (S2) apresentaram deficiência de $\mathrm{N}$ nas folhas. Esse equilíbrio provavelmente foi alcançado devido às proporções da mistura nos substratos, e a parte do substrato de casca de pínus forneceu boa aeração para o desenvolvimento das raízes e tinha a estabilidade que é necessária para o substrato, enquanto o composto de lixo orgânico ajudou na retenção de água.

\section{CONCLUSÕES}

Com relação à época de enxertia, o substrato 3 (S3), composto de $60 \%$ de casca de pínus e $40 \%$ de lixo orgânico, foi considerado o melhor, evidenciando a possibilidade de utilização do composto de lixo orgânico para a produção de mudas cítricas.

O substrato 1 ( $\mathrm{Si}$ ), composto de $100 \%$ de casca de pínus, proporcionou melhor desenvolvimento das plantas até quando essas foram supridas de nutrientes pelo fertilizante químico (quatro meses após o transplantio dos porta enxertos), e no final do experimento foi o pior tratamento.

O substrato 5 (S5), com $100 \%$ de composto de lixo, não promoveu bom desenvolvimento das plantas de cítrus, não sendo viável a sua utilização em plantios comerciais.

O nível de irrigação 3 (13), que correspondeu a $150 \%$ da evaporação do atmômetro, foi o que proporcionou o melhor desenvolvimento das plantas em todos os substratos.

\section{REFERENCIAS}

AGRIANUAL 2003. anuário da agricultura brasileira. São Paulo: FNP Consultoria e Comércio, 2003. p.295-6.

ALCOFORADO, P.U.G.; TRINDADE, A.V. Efeito do composto de lixo urbano nos teores de metais e outras características químicas do solo. In: FREITAS, P.L. (Ed.). Cerrados: fronteira agrícola no Século XXI. Goiânia: SBPS, 1993. p.307-8.

ARMSTRONG, A.C.; BURT, T.P. Nitrate losses from agricultural land. In: BURT, T.P.;

HEATHWAITE, A.L.; TRUDGILL, S.T. (Ed.) Nitrate: processes, patterns and management. England: Wiley, 1993. p.239-67.

BERNARDI, A.C.C.; CARMELLO, Q.A.C.; CARVALHO, S.A. Macronutrientes em mudas de citros cultivadas em vasos em resposta à adubação NPK. Scientia Agrícola, Piracicaba, v.57, n.4, p.761-7, 2000.

BRONER, I.; LAW, R.A.P. Evaluation of modified atmometer for estimating reference ET. Irrigation Science, New York, v.12, p.21-6,1991.

CONSTRUFERT. Composto orgânico. São Jose do Rio Preto: [s.n.], [19--].

FOLEGATTI, M.V.; SCATOLINI, M.E.; PAZ, V.P.S.; PEREIRA, A.A.R.; FRIZONE, J.A. Efeitos da cobertura plástica sobre os elementos meteorológicos e evapotranspiração da cultura de crisântemo em estufa. Revista Brasileira de Agrometeorologia, Santa Maria, v.5, n.2, p.155-63, 1997. 
GRASSI FILHO, H.; PEREIRA, M.A.A.; SAVINO, A.A.; RODRIGUES, V.T. Efeito de diferentes substratos no crescimento de mudas de limoeiro 'cravo' até o ponto de enxertia. Laranja, Cordeirópolis, v.22, n.1, p.157-66, 2001.

HERNANDEZ, T.; GARCIA, C.; COSTA, F.; VALERO, J.A.; AYUSO, M. Utilización de resíduos urbanos como fertilizantes orgânicos. Suelo Planta, San José, v.2, p.373-83, 1992.

INSTITUTO BRASILEIRO DE GEOGRAFIA E ESTATÍSTICA. Departamento de Cartografia. Carta do Brasil: Jabuticabal, Taiúva e Pitangueiras. São Paulo; 1971. Escala 1:50.000.

KIEHL,E.J. Fertilizantes orgânicos. São Paulo: Agronômica Ceres, 1985. 492 p.

LIMA, J.E.O. Produção de mudas na África do Sul. Laranja, Cordeirópolis, v.14, n.1, p.127-36, 1993.

MATTOS, D.J.; QUAGGIO, J.A.; CARVALHO, S.A.; ABREU, M.F. Substrato para produção de mudas cítricas em recipientes: Caracterização da toxidade de Boro. Laranja, Cordeirópolis, v.16, n.1, p.251-4, 1995.

MILNER, L. Water and fertilizers management en substrates. In: INTERNATIONAL CONGRESS OF CITRUS NURSERYMEN, 6., 2001, Ribeirão Preto. Proceedings... p.93-5.

OLIVER, E.N. A água nossa de cada dia preservai hoje! Coopercitrus, São Paulo, v.14, n.162, p.14, 2000.

SGANZERLA, E. Nova agricultura: a fascinante arte de cultivar com os plásticos. 4.ed. Porto Alegre: Livraria e Editora Agropecuária, 1991. p.49-83

STRINGHETA, A.C.O.; FONTES, L.E.F.; LOPES, L.C.; CARDOSO, A.A. Crescimento de crisântemo em substrato contendo composto de lixo urbano e casca de arroz carbonizada. Pesquisa Agropecuária Brasileira, Brasília, v.31, n.11, p.795-802, 1996.

STURION, J.A Métodos de produção e técnicas de manejo que influenciam o padrão de qualidade de mudas de essências florestais. In: SEMINÁRIO DE SEMENTES E VIVEIROS FLORESTAIS, 1., 1981, Curitiba. Anais... v.2, p.26.

VINTEN, A.J.A.; SMITH, K.A. Nitrogen cycling in agricultural soils. In: BURT, T.P.;

HEATHWAITE, A.L.; TRUDGILL, S.T. (Ed.) Nitrate: processes, patterns and management. London: Wiley, 1993. p.39-73.

VIOLANTE NETTO, A.; RAIJ, B. van; BLASCO, E.E.A.; VITTI, G.C.; CANTARELLA, H.; TEÓFILO SOBRINHO, J.; QUAGGIO, J.A.; NEGRI, J.D.; RODRIGUEZ, O.; BATAGLIA, O.C.; MALAVOLTA, E. Recomendações de adubação e calagem para citros no Estado de São Paulo. Cordeirópolis: Estação Experimental de Limeira, 1988. 13 p. 